\title{
TRANSFORMACIONES RECIENTES EN LA INDUSTRIA PETROLERA ARGENTINA: EL CASO DE YACIMIENTOS PETROLÍFEROS FISCALES, 1989-2012
}

\author{
Esteban Serrani \\ Universidad Nacional de San Martín, Argentina \\ eserrani@unsam.edu.ar
}

\section{RESUMEN}

El objetivo central del artículo es analizar el derrotero de la empresa estatal petrolera Yacimientos Petrolíferos Fiscales (YPF), desde la privatización hasta su renacionalización (1989-2012). En tal proceso, se presta especial énfasis en la identificación y el análisis de las particularidades nacionales que permiten explicar por qué en los años noventa YPF, una de las empresas nacionales más importantes de la historia, fue completamente privatizada (a contramano de la experiencia regional en México, Venezuela y Brasil); y cómo, tan sólo veinte años después, la misma firma volvió a estar en dominio estatal, con una expropiación que contó con amplio respaldo popular y parlamentario. En este sentido, para explicar esta trayectoria se repasan las principales consecuencias de la desregulación y la apertura en el sector petrolero, especialmente en el desempeño de REPSOL desde que adquirió la casi totalidad de acciones de YPF en 1999.

Palabras Claves: YPF, Empresas públicas, Petróleo, Desarrollo económico, Argentina. 


\title{
RECENT TRANSFORMATIONS IN THE ARGENTINE OIL INDUSTRY: \\ THE YPF CASE, 1989-2012
}

\begin{abstract}
The objective of the paper is to analyze the path of the state oil company YPF, from privatization to its expropriation (1989-2012). In this process, it has a special emphasis on the identification and analysis of national peculiarities that explain why in the '90s YPF, one of the nation's premier companies in history, was fully privatized (counter to the regional experience in Mexico, Venezuela and Brazil); and how, just twenty years later, the same company was again in state control, with an expropriation which was widely popular and parliamentary support. It also reviews the main consequences of deregulation and the opening in the Argentine oil sector, especially in the performance of --- since acquired all shares of YPF in 1999 , to explain this path.
\end{abstract}

Keywords: YPF, Public Companies, Oil, Economic development, Argentina. 


\section{INTRODUCCIÓN}

La Ley N. ${ }^{\circ} 26.471$ de Soberanía Hidrocarburífera de la Republica Argentina, sancionada el 3 de mayo de 2012, ha significado un cambio transcendental en la concepción dominante respecto a la explotación de los recursos naturales en general, y del petróleo y el gas en particular. En dicha ley, se declaró de interés público nacional el logro del abastecimiento energético interno como todas las actividades de explotación e industrialización de hidrocarburos en los diversos segmentos de la industria, a fin de garantizar "el desarrollo económico con equidad social".

En este marco, los hidrocarburos pasaron a significar un recurso estratégico para las actividades productivas del país, dejando de ser considerado como un commodity, es decir, una simple mercancía exportable desacoplada de la dinámica productiva nacional y que se rige por la lógica del mercado global de futuro. En este sentido, la ley también ordenó la expropiación del 51\% del patrimonio de YPF, la primera petrolera estatal del continental y que durante setenta ańos fuera la insignia de las funciones empresariales desempeńadas por el Estado argentino.

El objetivo central del artículo es analizar el derrotero de la trayectoria de la empresa estatal petrolera YPF, desde la privatización hasta su renacionalización (1989-2012). En tal proceso, se presta especial énfasis en la identificación y el análisis de las particularidades nacionales que permiten explicar por qué en los noventa YPF, una de las empresas nacionales más importantes de la historia fue completamente privatizada (a contramano de la experiencia regional en México, Venezuela y Brasil); y cómo, tan sólo veinte años después, la misma firma volvió a estar nuevamente en dominio estatal, con una expropiación que contó con vasto respaldo popular y parlamentario. En este sentido, se repasan las principales consecuencias de la desregulación y la apertura en el sector petrolero argentino, especialmente en el desempeño de REPSOL desde que adquirió la casi totalidad de acciones de YPF, en 1999, para explicar esta trayectoria.

\section{BREVE RESEÑA DE LA YPF ESTATAL}

La temprana búsqueda de petróleo en Argentina constituye un caso paradigmático en América Latina. Los primeros esfuerzos datan de mediados del siglo XIX (1855), cuando a pedido del gobierno nacional se le solicitó al geólogo francés Antonio Martín de Moussy que realizara un estudio sobre las características minerales y el potencial hidrocarburífero del país (Salas 2007). Sin embargo, no fue hasta 1907 que se encontró el primer yacimiento de hidrocarburos en Comodoro Rivadavia, virtud a la inversión estatal por desarrollar una industria vital para sostener el 
crecimiento de las actividades agropecuarias, como el transporte y la urbanización creciente.

Así fue como en 1922, bajo una mirada estratégica de los recursos naturales, el Estado Nacional fundó la primera petrolera estatal del continente: YPF, que desde sus orígenes estuvo integrada verticalmente a través de toda la cadena productiva petrolera. YPF fue desarrollándose como un oligopolio público sobre el sector, incrementando su producción a medida que descendía lentamente la participación de las empresas privadas, que habían desembarcado en el país desde finales del siglo XIX (Barrera 2011).

El resguardo y control del Estado sobre el sector de hidrocarburos por intermedio de YPF se fue profundizando a medida que se consolidaba el proceso de industrialización por sustitución de importaciones, régimen que exigía un permanente abastecimiento energético a bajo costo ${ }^{1}$. Con la llegada del peronismo al poder (1946-1955) se dinamizó la industrialización acelerada incrementándose la demanda petrolera interna, situación que favoreció el desarrollo de YPF. Sin embargo, la trayectoria de la petrolera estatal no estuvo exenta de controversias entre los partidarios de un monopolio íntegramente estatal y aquellos que defendían la participación de las petroleras privadas en el mercado (Sabbatella y Serrani 2011). Luego del golpe militar a Juan Perón en 1955, esa tensión se expresó fuertemente bajo el gobierno de Frondizi (1958-1962), quien había arribado al poder en 1958 con su experiencia conocida como desarrollista. Frondizi, con la finalidad de ampliar la explotación petrolera, generó un conjunto de contratos de locación de obra y servicios para YPF con varias de las empresas trasnacionales más importantes radicadas en el país, como Standart Oil de California, Esso o Shell. Luego del golpe militar a Frondizi en 1962 y al recibido por el Presidente Illia en 1966, se impuso un nuevo gobierno de facto liderado por el General Onganía, quien sancionó la ley de Hidrocarburos 17.319, que sigue aún vigente en 2012.

Sin embargo, la fuerte liberalización del sector comenzó en 1976 con

I El desarrollo de la industria petrolera, tanto latinoamericana como Argentina se da en el marco de la profundización de la intervención económica del Estado a partir de la implementación del modelo conocido como de industrialización por sustitución de importaciones. En este sentido, son varios los trabajos que han estudiado las distintas dimensiones del desempeño empresarial del Estado durante ese período (Ayala Espino 2000, Guajardo Soto 2008, Marichal 2008), poniendo el foco de atención en la creación, organización y evolución de algunas empresas industriales públicas, así como en la intervención del Estado en la gestión de empresas privadas durante este periodo (Bellini y Rougier 2008, Rougier 2010). 
el sexto golpe cívico-militar de la historia argentina². Allí, se inició la privatización periférica ${ }^{3}$ de importantes actividades de YPF, brindando mayor participación a empresas locales en la explotación de los yacimientos mayoritariamente descubiertos por la inversión estatal (Serrani y Castellani 2010), a través de contratos de explotación y de servicios para realizar tareas que YPF ejecutaba a un costo menor. Además, se dio origen a una política de precios desfavorable a la petrolera estatal, y su utilización como tomadora de fondos del exterior para realizar colocaciones financieras en el mercado interno, dejaron a YPF en una crítica situación de endeudamiento a la vuelta de la democracia, en 1983 (Sabbatella 2012). Así, el endeudamiento se constituyó en la condición de posibilidad del inicio de una política de apertura hacia la participación del sector privado, como fueran los planes petroleros del presidente constitucional Raúl Alfonsín (Huergo; Houston; Olivos; Petroplan), que tendieron a profundizar la apertura del sector a la participación privada, proceso que culminó cuando Carlos Menem llegó al gobierno en 1989.

A pesar del creciente proceso de liberalización del sector petrolero nacional y de privatización periférica de importantes actividades que desde los inicios cumplía YPF, hacia finales de la década del ochenta seguía siendo un instrumento fundamental para la planificación pública no solo del resguardo de la matriz energética, sino también para fijar precios internos

2 Tempranamente en la historia economía argentina, Schvarzer (I979, I982), Ferrer (I98I) y Canitrot (I980, I983) se encargaron de estudiar el carácter desindustrializador y favorable a las actividades especulativas que conllevaba la política económica impulsada en la región por las dictaduras militares desde finales de los sesenta y durante los setenta. Según estos autores, la misma formaba parte de un proyecto político más amplio de reestructuración de la sociedad populista que iba en detrimento de la intervención estatal en la economía. Así, entendieron que el diagnóstico realizado por la dictadura cívico-militar no era otra cosa que un intento de reconstitución de la relación entre sociedad civil y Estado, y por ende, de fundar un nuevo vínculo entre el Estado y los empresarios.

3 Durante este período se iniciaron las políticas de corte neoliberal, que apuntaron a la liberación comercial, la desregulación financiera y la privatización periférica de las empresas de servicios públicos, entre ellas, YPF. Este proceso declinó sistemáticamente la forma típica de intervención estatal en la economía del modelo de sustitución de importaciones, en pos de una mayor participación de las empresas privadas en el ordenamiento económico. La proliferación de contratos petroleros para las empresas privadas del sector fue una constante durante la dictadura, abriendo paso a un nuevo sistema de organización mixto de la industria. Áreas en potestad de la empresa estatal se entregaron a las firmas privadas con poco claras contraprestaciones establecidas (la mayoría incumplibles sin mediar una fuerte y decidida reinversión de utilidades), al mismo tiempo que la empresa estatal quedaba comprometida a adquirir el petróleo extraído, muchos veces a valores superiores a los propios costos y en algunos casos superiores al precio internacional. Para mayor detalle, véase Schvarzer (I982), Castellani (2009), Schorr (2005), Serrani (2012). 
y tener un control sobre la dinámica de la oferta interna, ya que hacia 1989 (Kozulj 2002):

1. El $62 \%$ de la extracción de petróleo corría por cuenta de la empresa estatal, mientras que el 35\% correspondía a las empresas contratistas que le entregaban su producción a YPF y un 3\% a viejas concesiones.

2. El rubro exploración históricamente fue desarrollado por la empresa estatal: desde su creación había realizado el $96 \%$ de los pozos exploratorios y había descubierto el $90 \%$ de las reservas comprobadas.

3. El 70\% de la refinación de petróleo estaba a cargo de las refinerías de YPF, mientras que sólo el 30\% restante era refinado por el sector privado

4. El peso a nivel demográfico y territorial de YPF se verificaba no sólo en el emplazamiento de infraestructura vial y comunitaria sino también en su extensa red de estaciones de servicio, llegando hasta zonas de muy baja densidad poblacional y por lo tanto de menor rentabilidad. Contaba con el $49 \%$ del mercado en las provincias centrales y el $67 \%$ en las provincias periféricas.

Sin embargo, nuevas ideas y una profunda reestructuración productiva, empresarial, del Estado y de las ideas dominantes llegarían con la nueva década. La industria petrolera, tanto regional como la argentina, no quedarían exentas.

\section{YPF Y LA TRANSFORMACIÓN NEOLIBERAL DEL MERCADO PETROLERO INTERNACIONAL}

A diferencia de los ochenta, a la década de los noventa no la precedió un escenario de precipitada suba de precios, de una fuerte incorporación de nuevos capitales a la industria petrolera, como tampoco de sustantivos cambios tecnológicos ni de suba de extracción. Por el contrario, parte central del escenario durante los ochenta estuvo marcada por una caída programada de la inversión, por la desaparición de aquellos pozos menos productivos (Bordenave-Gassedat 2011), como por un cambio en las relaciones de poder entre el cartel de empresas privadas que dominaron la industria desde sus inicios hasta los setenta (conocidas como las Siete Hermanas) ${ }^{4}$ y la emergencia de las petroleras estatales, mayoritariamente

$4 \quad$ Las Siete Hermanas estaban compuestas por las empresas norteamericanas Standard Oil de New Jersey, Standard Oil de New York, Standard Oil de California, Gulf Oil Corporation, Texaco, por la anglo-holandesa Shell y por la inglesa Brithish Petroleum. 
nucleadas en la OPEP.

Durante los noventa se mantuvo una tendencia cíclica declinante en los precios internacionales del crudo, no obstante la fase de recuperación que mostró en algunos meses de los dos primeros años de aquella década, a partir de conflicto bélico entre Irak y Kuwait. Esta tendencia cíclica a la baja en los precios internacionales del crudo, asociado a la creciente financiarización de la economía global (Ugarteche 2012), trajo aparejado profundos desequilibrios económicos, presupuestarios y financieros para los países exportadores (con especial acento en los latinoamericanos, como México y Venezuela) (Bonilla Sánchez y Suárez Guevara 2008). Esta situación global terminaría en la abrupta caída de precios de 1998-1999, situación que llevó a los principales países de la OPEP a firmar acuerdos para reducir la extracción de crudo, y con ello, intentar frenar la caída.

Pero no sólo la tendencia a la baja de los precios llevó a un recorte acordado en la extracción como estrategia para contenerlos en la arena internacional, sino que la década de los noventa también refleja las estrategias de valorización del capital asociadas a la caída de la inversión privada en exploración petrolera. Resulta innegable advertir que las grandes inversiones petroleras en exploración siguieron siendo realizadas por las petroleras estatales. Incluso en esta década, como respuesta al creciente poder de las empresas estatales, los ejecutivos de las grandes empresas privadas, sobre todo norteamericanas, llevaron adelante negociaciones para iniciar fusiones corporativas y compras inducidas a fin de concentrar la dispersión de firmas privadas (situación que impedía acrecentar la dimensión global de sus negocios). Se pueden destacar la asociación entre Exxon y Mobil (dos ex Standard Oil y miembros de las Siete Hermanas) como también la de British Petroleum con la norteamericana AMOCO, ambas en 1998; asimismo la de Chevron (ex Standard Oil de California) con Texaco en 2001. Producto de estas megafusiones, muchos de las más grandes empresas trasnacionales fueron comprando otras empresas independientes más pequeńas, favoreciendo la centralización del capital trasnacional en un período de creciente globalización neoliberal, consolidando la estructura verticalmente integrada de las grandes corporaciones como estrategia de valorización del capital petrolero.

Sin lugar a dudas, la articulación entre la tendencia a la baja en los precios internacionales y las estrategias de reestructuración y centralización del capital reflejan la batalla constante entre Estado y capital, entre empresas públicas y privadas, entre países desarrollados y emergentes, entre occidente y oriente por la captación de la renta petrolera internacional y por la capacidad de fijar los precios de forma oligopólica. En el marco más general de las estrategias del capital petrolero concentrado, en asociación 
con el capital financiero internacional, se produjo un marcado nuevo desembarco de inversiones extranjeras en América Latina, acompañando las estrategias de desregulación financiera, apertura comercial y privatizaciones de empresas estatales llevadas adelante gubernamentalmente en esta década. Los noventa significaron una fuerte oleada de trasformaciones en los principales países petroleros de la región.

En Brasil, por ejemplo, en 1995, luego de cuatro décadas de monopolio estatal a través de Petróleo Brasileiro (Petrobras), se generó cierta apertura del sector al aprobarse en el Parlamento la llamada Enmienda Constitucional N. ${ }^{\circ}$ 9, que permitió el ingreso de inversiones privadas a las actividades de los hidrocarburos. A mediados de 1997, se sancionó la Ley N. ${ }^{\circ} 9.478$ (Ley del Petróleo), que inició la desregulación y la apertura comercial tanto para el capital nacional como para el trasnacional. Sin embargo, el gobierno federal conservó la mayoría de las acciones ordinarias de Petrobras, que son las que le aseguran tener control político sobre las decisiones de la empresa. Incluso, aunque se implementaron rondas de licitaciones de yacimientos estatales, el Estado nacional protegió el rol protagónico de su petrolera en la llamada Ronda Cero (Serrani 2013), al ratificar en agosto de 1998 los derechos de Petrobras sobre una gran porción de los yacimientos en las zonas de mayores reservas certificadas.

En Venezuela, luego de la nacionalización petrolera de 1975 y de la creación, un año más tarde, de Petróleos de Venezuela Sociedad Anónima (PDVSA), las transformaciones de los noventa buscaron relajar el monopolio estatal. En articulación con el Plan Corporativo de Largo Plazo de PDVSA, en 1991 el Parlamento autorizó en la región más fértil del país, la Faja del Orinoco, la entrada del capital privado a las actividades de exploración y extracción de crudo mediante tres tipos de asociaciones. La primera, de explotación de campos marginales (1992). La segunda, reglada en 1993 por el Congreso y llevada a cabo a partir de 1995, de asociación estratégica de explotación entre el capital privado y PDVSA. Finalmente, a partir de 1996, los contratos de exploración de nuevos yacimientos permitieron, luego de veinte ańos, el ingreso de inversiones extrajeras en exploración (Campodónico 2004). Sin embargo, a pesar de la desregulación, PDVSA es una empresa del Estado cuyo capital social es propiedad en un $100 \%$ de la República Bolivariana de Venezuela, y mantiene a través de su empresa una posición dominante en todos los segmentos de la industria.

México, tentado por el aluvión privatizador y aun teniendo gobiernos pro-reformas de mercado, el Estado mexicano logró mantener el dominio sobre el petróleo, en base a las disposiciones constitucionales que establecen el total monopolio estatal sobre toda la cadena productiva del sector y el control de la totalidad accionaria sobre Petróleos Mexicanos (Pemex). No 
obstante, a causa del endeudamiento crónico de Pemex durante los ochenta (similar al de YPF), durante los noventa se fueron abriendo algunos pocos segmentos de la industria para la participación del capital privado. Así fue que en 1989 se desreguló una parte de la petroquímica, habilitando la inversión privada en sólo 14 productos básicos y en 734 de 800 productos secundarios, pasando a representar la inversión privada en petroquímica secundaria el $75 \%$ de la inversión total. Finalmente, en 1995 se modificó el artículo 27 de la Constitución para permitirle al capital privado la comercialización del gas natural (Clavijo y Valdivieso 2000).

En definitiva, el paso del neoliberalismo por la industria petrolera de la región dejó su huella. Pero en ninguno de los tres mayores productores fueron tan profundas como para que los estados perdieran el control estratégico sobre la industria ni sobre sus empresas petroleras. Ya sea como mecanismo de financiamiento estatal, como insumo para mantener el abastecimiento o como palanca para dinamizar los procesos de reindustrialización, las petroleras estatales siguieron siendo instrumentos centrales en las ecuaciones económicas de las grandes potencias industriales de la región.

Pero este no fue el caso de Argentina ${ }^{5}$.

\section{LAS REFORMAS NEOLIBERALES EN ARGENTINA Y LA PRIVATIZACIÓN DE YPF, 1989-2001}

Luego de la salida anticipada del gobierno de Alfonsín a principios de 1989, acelerada por la crisis económica, energética y la hiperinflación, un fuerte proceso de reestructuración social fue llevado adelante en la sociedad argentina en base al ideario neoliberal (Basualdo 2006, Schorr 2005). Éste sostenía que gran parte de la crisis económica de la década del ochenta en la región se debió a la existencia de un Estado deficitario e ineficiente para regular la existencia de monopolios y las formas monopólicas de acción económica (Krueger 1974) y que, por su elevada participación en la economía, recurrentemente acudía a la emisión monetaria para sostener el gasto público, emisión que en el tiempo reproducía progresivamente la espiral inflacionaria. En este imaginario neoliberal dominante de las ciencias económicas y de la gestión estatal, se llevaron adelante las reformas

5 Para un análisis pormenorizado de las distinciones en los impactos de las reformas neoliberales en los distintos países de América Latina, puede consultarse Sáinz y Calcagno (1999) y Penha Cysne (2000) para Brasil; Antelo (2000) para Bolivia; Correa (2002) para Ecuador; Bension (2006) para Uruguay; Pasco-Font (2000) para Perú, Clavijo y Valdivieso (200o) para México, entre otros. Sobre el caso especifico de Argentina, Schorr (2005) y Basualdo (2006), Pucciarelli (20 I I), entre otros. 


\section{estructurales en Argentina ${ }^{6}$.}

En efecto, la privatización de YPF ha sido la venta más importante de una empresa pública que se haya realizado en Argentina, no sólo por la magnitud del monto que se manejó en tal operación, sino por qué en varios aspectos fue novedosa respecto a las anteriores privatizaciones. Por un lado, fue la primera empresa estatal que se privatizó a través de una oferta pública inicial de acciones, es decir, sin que hubiera una participación previa del sector privado en la misma empresa. Por otro lado, fue la primera experiencia de colocación de acciones en el país de acuerdo al método conocido como book building7. De esta manera, la venta de YPF abrió el camino para que las acciones y títulos de Argentina tuvieran inserción en el mercado internacional con una calificación similar a las de otros países considerados de ingresos medios.

En este sentido, es posible organizar el análisis del proceso de privatización de YPF en tres etapas, diferenciadas sobre todo por los distintos componentes cualitativos que cada uno de ellos presenta. La primera etapa se extiende desde la sanción de las primeras leyes de reforma estructural hasta la puesta en marcha la desregulación de los precios internos (septiembre de 1989 - diciembre de 1990). La segunda etapa está comprendida desde la desregulación interna de precios de los combustibles

6 Si bien es cierto que las reformas estructurales impactaron, aunque de forma disímil, en el conjunto de países latinoamericanos, en caso argentino resulta uno paradigmático en virtud de la profundidad de la penetración del ideario neoliberal. En este sentido, desde la sociología económica, varios trabajos analizaron cómo en los ochenta, las operaciones ideológicas de intelectuales, economistas y think tanks fueron eficaces para plantear la implementación de las reformas estructurales promovidas por el diagnóstico neoliberal como única salida político-institucional al estancamiento económico y al régimen de alta inflación (Heredia 2004, Camou I 997, Strauss 2009). En este sentido, la irrupción del neoliberalismo no se explica sólo por los factores económicos estructurales, sino también por la presencia de una determinada configuración simbólico-ideológica expresada por un amplio conjunto de actores sociales (Beltrán 20 I I, Strauss 2009). Así, la creciente difusión de estas ideas anti-estatistas y su más difusa aceptación en los sectores ligados a los sondeos de mercado y la opinión pública, fueron tema de varios estudios sobre la eficacia de la relación entre economía y política, y entre tecnocracia profesional e intervención estatal en la esfera pública en tanto factor explicativo de este singular proceso (Beltrán 201 I, Heredia 2004, Pucciarelli 2002, Sidicaro 2001).

7 Comúnmente se define a una estrategia de book building como el proceso de consulta y testeo de la potencial demanda de inversores sobre ciertas acciones de determinadas empresas, a fin de comprobar cuánto el mercado estaría dispuesto a pagar por ellas. En definitiva, lo que se buscaba era cotejar fuera del mercado la demanda de los inversores para ajustar el precio de cada acción. Sin embargo, como se analiza más adelante en el caso de YPF, este mecanismo sirvió para subvaluar el precio inicial de las acciones. 
y culmina en el origen del proceso de privatización de YPF SE (enero de 1991-agosto de 1992). La tercera etapa se desarrolla en el propiamente dicho proceso de privatización de YPF (que comienza en septiembre de 1992 y finaliza en 1999).

En la primera etapa, (septiembre de 1989-diciembre de 1990), tanto el gobierno como el conjunto de petroleras privadas no tenían dudas respecto a la necesidad de avanzar en una completa desregulación sectorial como en la privatización de YPF. Sin embargo, la pregunta sin respuesta en aquellos días era: ¿qué privatizar de YPF y cómo hacerlo? Para ello, se estableció una inaugural batería legislativa de leyes y decretos que permitieron avanzar en la desregulación del sector. Estos cambios en la legislación sectorial habilitaron la reconversión de los contratos petroleros que los agentes privados tenían con YPF hasta ese momento, muchos de ellos originados durante la última dictadura militar y el gobierno de Alfonsín. La Ley de Reforma de Estado (N. $\left.{ }^{\circ} 23.696 / 1989\right)$, por ejemplo, abrió el proceso de transformación estructural del sector permitiendo una nueva renegociación de los contratos petroleros. La nueva legislación les aseguraba a los agentes privados un mayor poder de decisión sobre las reservas de los pozos licitados, en tanto los antiguos contratos de extracción y explotación de crudo se reconvirtieron en contratos de concesión o asociación por un lapso de veinticinco años, a los que se sumaba una ventaja adicional: la libre disponibilidad de los productos obtenidos. Paralelamente, la Ley de Emergencia Económica (N.2 23.697/1989) profundizó los cambios estructurales en el sector: suspendió los subsidios y los descuentos tarifarios a la industria, desafectando el Fondo Nacional de Energía, y desalentó el control estatal de precios hasta que el mercado estuviera completamente desregulado. Por último, esta ley fijó los lineamientos generales sobre las regalías petroleras que el Estado recibiría una vez privatizada YPF.

Específicamente sobre la industria petrolera, el gobierno del presidente Menem dictó cuatro decretos a los pocos días de asumir en 1989, organizando el camino hacia la privatización de YPF.

El primero de ellos fue el Decreto N. ${ }^{\circ} 1.055 / 1989$, donde se definió la necesidad de aumentar la productividad total del mercado a través de reactivar la explotación de petróleo mediante un "necesario proceso de desregulación”. De esta manera, el Estado dejaba de tener injerencia en el control estratégico del sector, para traspasar los mecanismos de control de la oferta y los de fijación de precios al mercado. Además, este decreto inició el proceso de concesión a las empresas privadas de áreas secundarias y asociación en las áreas centrales de YPF.

El segundo fue el Decreto N. ${ }^{\circ} 1.212 / 1989$, que profundizaba la 
desarticulación de YPF al reconvertir los contratos en concesiones y ampliaba la oferta de libre disponibilidad. El Estado transfirió al oligopolio privado la potestad de la fijación de los precios, las cantidades asignadas por empresa, los valores de las transferencias y las bonificaciones a los actores perjudicados en las distintas etapas de la industria, ampliando la desregulación. Se buscaba, además, que los precios domésticos se ajustaran a los internacionales y que la fluctuación de los primeros reflejara la evolución de los segundos. Por último, ratificaba la libertad para importar y exportar hidrocarburos.

Finalmente, el Decreto N. ${ }^{\circ} 1.589 / 1989$ consolidó las disposiciones anteriores y amplió ciertos mecanismos desregulatorios al garantizar la eliminación de aranceles y derechos de exportación y la libre disponibilidad del $70 \%$ de las divisas que obtuvieran de la venta tanto en el mercado doméstico como en el internacional del petróleo y/o sus derivados.

En la segunda etapa, desde el inicio de la desregulación de precios hasta el origen del proceso de privatización de YPF (enero de 1991-agosto de 1992), para poder encarar su venta se buscó reestructurar la empresa hacia un perfil más acorde al de una firma privada. En virtud de este objetivo, se fraccionó la firma en diferentes unidades de negocios, vendiéndose por separado aquellos activos que eran considerados no-estratégicos para la nueva morfología empresarial que se deseaba para YPF. El Decreto N. ${ }^{\circ}$ 2.778/1990 impulsaba el Plan de Transformación Global, que convirtió la petrolera estatal en una sociedad anónima y estableció un calendario de venta de sus activos. En el artículo 18 se reconfiguraba el mercado distinguiendo dos tipos de unidades a licitar: las del mercado primario y las del mercado secundario. De esta manera se presentó la estructura legal para la enajenación de activos y reservas que la nueva YPF vendería por considerarlos no estratégicos.

La valuación de las reservas de petróleo (y gas) de YPF quedó en manos de la consultora internacional Gaffney, Cline y Asoc., quien según diversos especialistas, realizó una fuerte subvaluación de las mismas: la estimación de la consultora fue un $28 \%$ inferior para el petróleo y el gas respecto a la reconocida oficialmente con anterioridad (Kozulj 2002) ${ }^{8}$. Por otro lado, el proceso de análisis y propuesta de transformación de la YPF fue

8 Las concesiones de los yacimientos de YPF representaron menos ingresos de lo que costaba realmente la empresa: los activos de YPF se estimaban en al menos US\$ 20.000.000.000 a pesar de que una valorización de esta consultora le atribuyó entre 3.000.000.000 y 4.000.000.000. Sin embargo, el Decreto 2.778/1990 las estimó en sólo US\$ I.I70.000.000 al capital social (Kozulj y Bravo I993, citado en Azpiazu 2003: I68), o sea, significativamente menos que lo estimado por la Consultora Gaffney, Cline y Asoc. 
delegado en otra consultora internacional: McKinsey \& Company. Este proyecto incluía la venta de activos de la empresa, la asociación con empresas privadas para la explotación de algunas áreas y la racionalización de la plantilla de trabajadores petroleros: de un total de 51.000 empleados (directos e indirectos) al finalizar 1990 se pasó a 7.500 tres años después, implicando una reducción de la nomina salarial de US\$ 51.000 .000 a US\$ 17.000.000 a finales de 1993 (YPF 1994).

La llegada en agosto de 1990 a la dirección de YPF del empresario del sector José Estenssoro ${ }^{9}$ no hizo más que profundizar la transformación promercado de la petrolera aun estatal. A pocos meses de asumir, los primeros pasos de su gestión al mando de la empresa apuntaban a desestatizar las formas de organización y gestión interna de la petrolera y reestructurar las cadenas productivas. Era preciso entonces redimensionar YPF a través de la desinversión en determinados activos que según la McKinsey \& Company eran no-estratégicos.

Específicamente en el segmento del mercado primario se transfirieron al sector privado importantes activos de las áreas centrales de YPF (las de mayores reservas probadas). Mediante el Decreto N. ${ }^{\circ} 1.216 / 1990$ se convocó a las empresas privadas a una precalificación para acceder en forma asociada al 50\% de las reservas recuperables de petróleo y gas en las cuatro áreas centrales. De esos contratos de asociación resultaron adjudicatarios cuatro consorcios de empresas, de los cuales tres estaban conformados por algunas de las mismas firmas que desde el comienzo de la privatización periférica de YPF habían sido sus contratistas ${ }^{10}$, aunque esta vez se presentaban asociadas a importantes multinacionales ${ }^{11}$. Sin embargo, lejos de percibir los (por lo menos) US\$ 800.000 .000 proyectados por la venta de las cuatro áreas petroleras centrales licitadas, el gobierno solo recibió cerca de US\$ 550.000.000. La pérdida de unos US\$ 250.000.000 fue exclusiva responsabilidad de la política de precios que por aquel entonces

9 Hijo del presidente boliviano Víctor Paz Estenssoro, quien llevó adelante en 1955 una profunda reforma petrolera, que con el llamado Código del Petróleo, permitió el ingreso de capitales privados al negocio de los hidrocarburos.

Io El yacimiento Vizcacheras (Mendoza) fue adjudicado a Pérez Companc (en asociación con Occidental Exploration of Argentina); El Tordillo (Chubut) a Tecpetrol (con Santa Fe Energy); y Puesto Hernández (Neuquén y Mendoza) a Astra (en asociación con REPSOL). El restante yacimiento, El Huemul (Santa Cruz), quedó en manos de Total Austral (de Francia).

I I Esta articulación de intereses entre los capitales concentrados locales, las empresas multinacionales y los bancos internacionales fue una de las más importantes estrategias que utilizaron los primeros para conseguir participar en las licitaciones de la privatización de diferentes empresas públicas (Basualdo 2006). 
implementaba YPF ${ }^{12}$ : en vez de colocar el crudo en el mercado local a US\$ 20 por barril (su precio internacional), lo vendía a US\$14. En una segunda etapa, se privatizaron los derechos de exploración a empresas privadas en las cuencas Noroeste y Austral, que estaban reservados para YPF. En cuanto a la explotación, se otorgó un $50 \%$ en calidad de asociación a empresas privadas. Al mismo tiempo, entre 1990 y 1991 se adjudicaron otras 86 áreas marginales (sobre 105 existentes) por un total de US\$ 470.000 .000 (Kozulj 2002).

En el segmento del mercado secundario, se privatizaron las refinerías de San Lorenzo, Dock Sud, Campo Duran, Luján de Cuyo, La Plata y Plaza Huincul, además de que se enajenaron importantes activos de la flota naval, de los talleres navales, puertos y otras plantas de la petrolera estatal. Este proceso de enajenación de reservas y venta de activos considerados noestratégicos para la nueva morfología que YPF iba adquiriendo, implicó un ingreso para el Estado de US\$ 2.059.000.000 por todo concepto (Kozulj 2002), y al mismo tiempo una caída del $40 \%$ en las reservas de YPF y de un 25 en la extracción de petróleo, entre 1991 y 1993 (YPF 1994).

Por último, la tercera etapa refiere al proceso mismo de privatización de YPF (septiembre de 1992-mayo de 1999). Una vez que la empresa estatal había sido reestructurada a semejanza de una petrolera privada, quedaba cerrar el proceso transfiriendo YPF mediante la cotización de sus acciones en los mercados bursátiles. Por aquel entonces, el gobierno de Carlos Menem, apremiado por la presión fiscal del peso de la deuda externa, esperaba que la venta de YPF le permitiera llegar a la más amplia cancelación de las deudas previsionales, colocando la mayor cantidad de acciones. Es decir, con activos pagar pasivos corrientes, pan para hoy, hambre para mañana.

Luego de muchas idas y vueltas, en septiembre de 1992 se sancionó la Ley N. ${ }^{\circ} 24.145$ de Federalización de los Hidrocarburos. A partir de esta ley, el Estado se reservaba el $51 \%$ de las acciones de la nueva sociedad anónima que se constituiría en reemplazo de la sociedad estatal. El 29 de junio de 1993 las acciones de YPF comenzaron a cotizar en la bolsa local. Por el $43,5 \%$ de las acciones se recibieron un total de US\$3.040.000.000 frescos, a razón de US\$19 por acción. Del total de la venta, el Estado nacional

I2 Algunas investigaciones más prudente aseguran "para las 4 áreas consideradas (que representaban apenas el i $8 \%$ de la producción total de los contratos reconvertidos) una pérdida para el Estado de I 50 millones de dólares" (Gadano y Sturzenegger I997, citado en Gadano I998: 21). Sin embargo, más allá de que el número final sea US\$ I 50.000 .000 en las proyecciones más prudentes o US\$250.000.000 en las menos, resulta evidente que la fuerte subvaluación de los activos estatales llevada a cabo por parte de los diferentes grupos de intereses significó una transferencia neta de ingresos a los actores concentrados del sector. 
recibió US\$ 1.700.000.000, y el resto fue para las provincias oferentes, personal de la empresa y tenedores de bonos de la deuda previsional. Luego de la oferta pública inicial, la estructura de las acciones quedó en un 45,3\% en poder del sector privado, y un $54 \%$ en poder del Estado nacional, las provincias y a disposición del personal de la empresa; mientras que la distribución por nacionalidad fue de una $34 \%$ para accionistas extranjeros y un $66 \%$ para accionistas argentinos.

Uno de los aspectos técnicos más singulares de la privatización de la petrolera estatal fue el hecho que los ingresos de la venta no fueron destinados a cubrir gastos ni déficit, sino a sanear la deuda pública. Mediante la cancelación de deudas previsionales, y la operación de compra de deudas, se rescataron títulos denominados Bonos de Consolidación de Deudas Previsionales y otras deudas en efectivo por un valor nominal cercano a los \$3.000.000.000 (YPF 1994). Sin embargo, en líneas generales, considerando la valuación que desde el Ministerio de Economía se fijó para cada acción, no caben dudas que fueron fuertemente subvaluadas ${ }^{13}$ (Azpiazu 2003, Barrera 2011, Kozulj 2002, Montamat 2005, Sabbatella $2011)^{14}$.

En el tiempo, el Estado nacional se fue desprendiendo por esta vía del $80 \%$ de su paquete accionario (a pesar de que la ley sancionada el año anterior establecía que el Estado nacional debía reservar para sí el 51\% de las acciones). Como consecuencia de este proceso de desprendimiento de las acciones estatales, hacia 1993 la participación accionaria quedó conformada de la siguiente manera: $20 \%$ más la acción de oro ${ }^{15}$ para el Estado nacional; $12 \%$ para las provincias; $10 \%$ para el personal de YPF SA; $12 \%$ para el sistema previsional; y $46 \%$ para los accionistas privados. Finalmente, en 1995 se dictó la Ley N. 24.474 (que modificaba a la Ley

I 3 En efecto, la muestra más clara de la subvaluación de acciones de YPF fue el hecho de que inmediatamente después de concretarse la oferta pública inicial, exactamente un día después, las mismas valían I 3,9\% más, llegando a cotizar en la Bolsa de New York a US\$2I,87 por acción. Esto supuso una inmediata transferencia neta de recursos a los flamantes accionistas de YPF de alrededor de US\$ 420.000.000.

I 4 Más allá de la estrategia de book building planteada para la conformación final del precio de cada acción de la petrolera estatal, la propia intervención estatal, a través de las declaración públicas del Ministro de Economía Domingo Cavallo, le había puesto tanto un piso como un techo a las mismas: entre US\$ I7 y 20 por acción, concretando la subvaluación por acción del valor final de YPF (La Nación, 29 de mayo de 1993).

I 5 Se denomina acción de oro a aquellas acciones que tienen derechos especiales de voto. Es decir que quienes la posean, tienen un poder especial con respecto a los demás accionistas. En el caso de las privatizaciones de empresas públicas, los Estados nacionales suelen reservarse estas acciones para tener ciertos derechos y controlar decisiones estratégicas de la sociedad privatizada. 
N. 24.145 de 1992) habilitando al Estado nacional a quedarse con, al menos, una acción de la empresa. La conformación accionaria hacia 1998, antes de la transferencia a REPSOL quedaba del siguiente modo: para el Estado nacional el $20 \%$ más la acción de oro; $4,7 \%$ para las provincias; 0,4\% para el personal de YPF; 74,9\% para los accionistas privados ${ }^{16}$. El proceso de desvinculación de los organismos públicos de la petrolera era cada vez mayor, tanto que a comienzos de 1999, fue vendido a la espańola REPSOL el 98,23\% de las acciones, desprendiéndose el Estado nacional y los gobiernos provinciales de la totalidad de sus participaciones accionarias en la empresa.

\section{LOS 2000 Y LA REORIENTACIÓN DE LAS POLÍTICAS PETROLERAS}

Luego de los traumáticos episodios de diciembre de 2001 y de la virtual (sensación de) desafección de las instituciones democráticas respecto de su fuente de legitimidad política al sucederse cinco mandatarios presidencias entre el 20 de diciembre 2001 y el 1 de enero de $2002^{17}$, el 2 de enero de 2002 la Asamblea Legislativa designó como Presidente Provisional al justicialista Eduardo Duhalde, que por aquel entonces se desempeñaba

I6 La participaciones accionarias de YPF hacia 1998 refleja el amplio proceso de extranjerización de la economía argentina, ya que los fondos de inversión extranjeros representaban un 63, I\% del total mientras que las participaciones de capital nacional era de tan sólo i I , 8\% (Pérez Companc 3,8\% y Bancos nacionales y AFJP, 8\%) (Kozulj 2002).

I7 Luego de los intentos fallidos de estabilización financiera, conocidos como blindaje financiero (diciembre de 2000) y megacanje (octubre-noviembre 200I), y de la mayor crisis económico y social del país desde la experimentada en I929, la gestión de la Alianza (partido en el gobierno entre i 999 y 200I) finalizó con la implantación de un corralito bancario ante la insolvencia del sistema financiero, que desembocó en los trágicos acontecimientos del i 9 y 20 de diciembre. La represión policial contra la manifestación popular coronaría la desintegración del poder estatal y la disolución de la continuidad del orden político-institución del país, plasmadas en la declaración del estado de sitio, la renuncia de Ministro de Economía Domingo Cavallo primero, del presidente De La Rúa después, y la incompresible muerte de treinta y nueve civiles en todo el país. En ese escenario, tras los hechos de diciembre de 200 I quedaba claro que el experimento neoliberal forjado en la convertibilidad había llegado a su fin. La forma típica del neoliberalismo argentino, también. Para la continuidad económica, emergieron sectores que pugnaban por la devaluación de la moneda frente a los que defendían la dolarización de la economía. Los enfrentamientos en el interior de los sectores dominantes se resolvieron de forma infausta. El cambio en la orientación de la intervención estatal respecto a la política cambiaria sucedería a los pocos días de iniciado el 2002, tras una mega devaluación que consagró una considerable pérdida de poder adquisitivo de los trabajadores, abriendo un escenario de profunda regresividad social, con indicadores sociales de pobreza y desempleo inéditamente altos en la historia argentina. 
como Senador Nacional por la provincia de Buenos Aires. A los pocos días de asumir, el gobierno duhaldista promulgó la Ley de Emergencia Pública y Reforma del Régimen Cambiario (N. ${ }^{\circ} 25.561$ ), que marcó la finalización de la convertibilidad cambiaria un peso igual a US\$ 1 , a través de la devaluación de la moneda nacional (llamada luego pesificación asimétrica ${ }^{18}$ ). Esta medida alteró la estructura de costos y precios relativos internos, profundizando la crisis económica al sostener una caída del $10 \%$ en el PIB total y en el industrial, con una marcada pérdida de poder adquisitivo de los asalariados de alrededor del $30 \%$ respecto a las ganancias de las grandes empresas vía pesificación de sus deudas dolarizadas (Azpiazu y Schorr 2010 CENDA 2010). Finalmente, otorgó poderes especiales al Ejecutivo para dirigir la economía, dada la situación de crisis sistémica por la que atravesaba el país.

Sin embargo, no fue hasta los gobiernos de Néstor Kirchner primero (2003-2007) y de Cristina Fernández de Kirchner después (primer mandato 2007-2011, segundo mandato 2011) que se evidenció un giro de la intervención estatal en la economía. Esta reorientación, proclive a dinamizar los procesos productivos en detrimento de la especulación financiera, apalancó un ritmo de crecimiento económico pocas veces experimentado en la historia argentina (sobre todo entre 2003-2008), además de una agresiva política de generación de empleo y de recuperación salarial que dinamizó el mercado interno, al mismo tiempo de una sustantiva caída de las tasas de pobreza y indigencia. Esta dinámica estructura económica estuvo salvaguardada en un equilibrio macro-económico (superávits gemelos: fiscal y comercial) además de la exitosa reestructuración de la deuda en default, llevada adelante en 2005 y 2010. Sin embargo, parte central de la estructura económica oligopólica de los grandes formadores de precios poco se alteró desde décadas anteriores, como tampoco se logró alterar la concentración y extranjerización de la economía (Azpiazu et al. 2012). Estructura que tendrá fuertes repercusiones en la dinámica de la industria petrolera, como en la toma de decisiones frente al constante escenario de crisis energética que el país vivió desde 2003, producto de, al menos, dos procesos concomitantes: el crecimiento sostenido de la demanda interna de energía y la constitución oligopólica privada de la oferta en toda la cadena petrolera ( $y$ energética en general).

En cuanto a la política petrolera especifica, los 2000 marcan un cambio del papel del Estado en la disputa de la renta con las empresas privadas y con un mercado completamente desregulado, heredado de los noventa.

En primer lugar, se desarrolló una política fiscal de captura de renta y

I 8 A modo de ejemplo, consultar Azpiazu y Schorr (2010) y CENDA (20 Io). 
manejo interno de precios. Con el Decreto N. ${ }^{\circ} 310 / 2002$ se volvieron a establecer derechos a la exportación (retenciones) de $20 \%$ al petróleo crudo y de $5 \%$ para los productos refinados que salieran del país. Este impuesto fue modificado primero en mayo de 2004, cuando se elevó el gravamen a 25\% (Resolución N. ${ }^{\circ} 337 / 2004$ ), y luego en agosto del mismo año al volverse móviles, pudiendo agregar al 25\% fijo, alícuotas variables entre 3 y $20 \%$ dependiendo si los precios internacionales estuvieron entre US\$32 y 45 el barril (Resolución N. ${ }^{\circ}$ 532/2004) hasta un máximo de retención del $45 \%$ del precio de exportación. En enero de 2007, el gobierno nacional promulgó la Ley $\mathrm{N} .^{\circ} 26.217$, que prorrogaba por cinco años la vigencia del derecho a la exportación sobre los hidrocarburos. Así, el nuevo esquema contempla una retención de $45 \%$ si el precio internacional West Texas Intermediate se ubica entre US\$ 45 y 60,89. Si el precio del barril es más bajo a US\$ 45, el gobierno nacional tiene un plazo de 90 días para definir un nuevo sistema de alícuotas. Pero llegado el caso de que el precio internacional superara los US\$ 60,98 el barril, la alícuota de exportación se calculará a partir de una fórmula que articula el precio internacional y el valor de corte interno, establecido por el gobierno nacional. En este sentido, la formula asume que no importa cuánto se incremente el precio internacional por sobre los US\$ 60,9, los exportadores sólo recibirán US\$ 42 por barril exportado (valor de corte), siendo la diferencia capturada por el Estado nacional.

En segundo lugar, se llevó adelante una profundización del dominio provincial sobre los yacimientos. En octubre de 2006, se llegó a la firma del Acuerdo Federal de Hidrocarburos, que luego finalizaría en la sanción de la Ley N. ${ }^{\circ}$ 26.197, llamada Ley Federal de Hidrocarburos (y prosaicamente conocida como ley corta), en diciembre de 2006. Respecto al Acuerdo Federal de Hidrocarburos, este radicó en la firma por parte del presidente de la nación y de los gobernadores de las provincias productoras ${ }^{19}$, de un acuerdo para hacer cumplir el párrafo segundo del artículo 124 de la Constitución Nacional (que ya había sido ampliado en el Decreto N. ${ }^{\circ}$ $564 / 2003)$, donde se consagra el dominio de las provincias sobre los recursos naturales, en este caso de los hidrocarburos. De esta manera, el acuerdo tanto como la ley profundizaba la política de fragmentación de la soberanía respecto a la toma de decisiones respecto a la definición de la orientación política en materia petrolera, iniciada en la Reforma Constitucional de $1994^{20}$.

I9 Tierra del Fuego, Antártida e Islas del Atlántico Sur, Santa Cruz, Chubut, Río Negro, La Pampa, Neuquén, Mendoza, Salta, Formosa, y Jujuy

20 Respecto a la provincialización o federalización de los hidrocarburos, se retoma la interpretación de Ignacio Sabbattella: 
En tercer lugar, se implementaron incentivos fiscales a la productividad en el marco de un prolongado descenso tanto de la extracción petrolera como de la inversión privada en exploración de riesgo. En noviembre de 2008, el Gobierno nacional puso en marcha bajo el Decreto N. ${ }^{\circ}$ 2.014/2008 los Programas Petróleo Plus y Refinación Plus ${ }^{21}$, buscando estimular las inversiones en exploración, explotación y refinación, e impulsar la incorporación de reservas. El primer plan, el Petróleo Plus, aspiraba a que se realizaran nuevas inversiones que elevaron los niveles de producción y reservas. Los incentivos estaban dados por la entrega de créditos fiscales, que serían usados para cancelar derechos de exportación. Se buscaba que esta transferencia de costos de producción impactara indirectamente en una mejora de los precios finales del crudo para el mercado interno. El segundo plan, el Refino Plus, se articulaba con el anterior, buscando ampliar la capacidad ociosa de refinación, estancada por largas décadas, inversiones que evidentemente habían sido nulas desde fines de los setenta. Este plan, asimismo, promovía incentivos fiscales para nuevas refinerías o para la ampliación de la capacidad de refinación en gasoil y nafta súper. Adicionalmente, se estableció un régimen especial de beneficios para pequeños refinadores no integrados. Sin embargo, expost, estos objetivos estuvieron lejos de concretarse debido a la reticencia de las empresas privadas de realizar inversiones en infraestructura o de

La federalización era un viejo anhelo de las provincias desde el comienzo mismo de la historia petrolera argentina. Las sucesivas administraciones provinciales y sus élites locales, fundamentalmente en Salta, Mendoza y Jujuy, habían mantenido una actitud celosa respecto a sus recursos naturales y hasta llegaron a la confrontación con los distintos gobiernos nacionales. En buena parte de los casos, preferían la negociación directa con las petroleras transnacionales y la no intromisión de la empresa estatal [...] En el marco de la transformación neoliberal del sector petrolero, el gobierno de Menem y los gobernadores de las provincias con hidrocarburos en su subsuelo acordaron a través del Pacto de Luján de I990 el reconocimiento del dominio y jurisdicción de los Estados provinciales sobre los recursos naturales renovables y no renovables, superficiales y subyacentes, que se encuentren en su territorio (2012: 166-168).

En esta misma dirección, la ley corta, sancionada en 2007 , no fue más que el reforzamiento por parte del gobierno nacional de lograr el apoyo de los gobernadores a su política energética, brindándoles amplios beneficios respecto a los recursos económicos productos del dominio provincial de los hidrocarburos, ya sancionados en la reforma constitucional de I994. Sin embargo, tal ley profundizó la desarticulación de la planificación nacional de la política petrolera, al otorgarle discrecionalidad a las provincias petroleras para sus negociaciones directas con las empresas privadas. Uno de los casos más visibles fue la renovación a Pan American Energy de la concesión de Cerro Dragón, yacimiento de los más importantes del país, diez años antes de su vencimiento, "sin que tuviera justificaciones basadas en criterios técnicos o productivos” (Ortiz 2008: 7, citado en Sabbatella 20 I 2: I68).

2 I Que en la Resolución N. ${ }^{\circ}$ I.312/2008 de Secretaria de Energía, ambos programas definirían sus objetivos y la forma de calcular los incentivos fiscales. 
riesgo, mientras que buscaron explorar en áreas con reservas comprobadas, descubiertas por inversión realizadas por YPF mientras era estatal (Barrera 2012, Serrani 2012)

Finalmente, se buscó una ampliación de la participación estatal y argentinización de los servicios públicos. Con la intención de reiniciar la participación estatal en las actividades productivas de la industria petrolera, en diciembre de 2004 se creó Energía Argentina Sociedad Anónima (ENARSA) mediante la Ley N. ${ }^{\circ} 25.943$. A ENARSA se le ha otorgado la titularidad de los permisos de exploración y concesiones de explotación de todos los bloques offshore del país (y que no estuvieran adjudicados a la fecha de su creación), con la finalidad de atraer inversiones de riesgo que se asocien estratégicamente con la nueva empresa estatal. Según información de la empresa, hasta fines de 2011, se habían constituido tres consorcios para exploración petrolera offshore, que sin embargo aún no han logrado su principal cometido: ampliar la dotación de reservas probadas de hidrocarburos. Al mismo tiempo, hacia finales de 2007 y principio de 2008, impulsado por el gobierno, el Grupo Petersen SA de la familia Eskenazi compró el 14,9\% de las acciones de YPF, con una opción para adquirir otro $10 \%$ dentro de los siguientes cinco años (opción que tomaría hacia finales de 2011). La operación se realizó por un total de US\$ 2.235.000.000, que si bien el grupo aportó US\$100.000.000, fue fondeada prácticamente en su totalidad por deudas contraídas por los compradores: US\$ 1.017.000.000 a través de un crédito con la propia REPSOL y otro préstamo con un un pool de bancos (Crédit Suisse, Goldman Sachs, BNP Paribas e Itaú) por US\$ 1.018.000.000. La argentinización del capital accionario de YPF con la entrada del grupo Petersen fue una animosa apuesta para frenar la decadencia en la que estaba sumergida la industria. La misma conjeturaba que con empresarios nacionales sería más fácil dialogar, articular y negociar; a fin de cuentas, disciplinarlos (Amsden 1991, Wade 1999). Sin embargo, REPSOL ya había tomado la estrategia de desinversión programa en YPF, y la entrada de Eskenazi, con una gran deuda asumida por la propia empresa de la cual ahora era accionista, dinamizó las estrategias cortoplacista de fuga de utilidades al exterior para asumir los compromisos financieros, financiar inversiones que REPSOL tenía en otros lugares (que sí eran considerados estratégicos) y finalmente, transferir gran parte de las ganancias a las accionistas. Es evidente que la llegada de la familia Esquenazi a YPF terminaría fracasando y generando grandes costos financieros para YPF.

Entonces, ¿cuál fue el derrotero de YPF bajo la gestión de la española REPSOL? 


\section{REPSOL EN ARGENTINA Y EL DESMANTELAMIENTO DE YPF}

El análisis de la performance de la empresa más indicativa del mercado petrolero nacional, sea en términos de cuotas de mercado como por el valor simbólico al haber comprado la empresa de bandera, permite comprender y explicar parte central del derrotero y desenlace de YPF. Cuando en 1999 REPSOL compró la totalidad del paquete accionario de YPF, le permitió integrar un sustancial stock de reservas de petróleo que le habilitó no sólo integrarse verticalmente equilibrando sus negocios del mercado primario con el secundario, sino también ubicarse como una de las diez petroleras más grandes del mundo en términos de reservas y capitalización de mercado

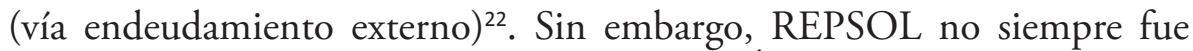
una de las empresas líderes a nivel mundial. Ésta nació en 1987 con un capital simbólico de 60.000 pesetas, creada por el Instituto Nacional de Hidrocarburos español a fin de reordenar su sector petrolero a partir de una empresa estatal, verticalmente integrada ${ }^{23}$. Sin embargo, a poco de crearse, comienza el proceso de privatización total de la empresa, que se desarrolló entre 1989 y 1997: primero a partir de la entrada del Banco Bilbao Vizcaya Argentaria (BBVA), canjeando su participación accionaria en una de las filiales (Petronor), por acciones de la nueva REPSOL; segundo a partir de la entrada de Pemex, quien adquiere el 5\% de las acciones (y también se hace de acciones de sus filiales: $88,3 \%$ de Campsa y 68 de Petronor); tercero, a partir de la cinco ofertas públicas de acciones de REPSOL que llevó adelante el Instituto Nacional de Hidrocarburos, que le permitió al Estado desprenderse de la totalidad de acciones de la empresa, sólo conservando la golden share, hasta febrero de 2006. En definitiva, hacia 1998 la composición accionaria de la REPSOL completamente privatizada quedaba de la siguiente manera: $35 \%$ en poder de fondos institucionales americanos, $24 \%$ en fondos institucionales españoles, $41 \%$ para otros fondos minoritarios (La Caixa con 5\%; el BBVA con 9,8; Pemex con 5; Endesa con 3,6, The Chase Manhattan Bank, con 5) (Kozulj 2002: 23).

Sin lugar a dudas, el entramado de intereses financieros de los accionistas de REPSOL, asociado a sus empresas controladas y vinculadas, y las potenciales a partir de una posible compra de YPF, volvían económicamente llamativa la operación sobre la petrolera argentina. Es que

22 El entramado empresario que conforma el paquete accionario de REPSOL España le permitió acceder a una facilidad crediticia de US\$ I 5.500.000.000 para la compra de YPF, que fue ofrecidos por un consorcio de entidades financieras, muchas de ellas accionistas de la propia empresa española, como el BBV y La Caixa, pero también otros como Goldman Sachs, Merril Lynch, Citigroup y la Unión de Bancos Suizos

23 En sus inicios, REPSOL SA tenía cinco filiales: Exploración (antigua Hispanoil), Petróleo (antigua Enpetrol), Butano (antigua Butano SA), Campsa y Petronor. 
REPSOL, si bien podía acceder el mercado de capitales internacional para financiar su internacionalización petrolera, era una empresa sin reservas. Paradójicamente, REPSOL tenía acceso a vigorosos financiamientos para un emprendimiento sobre el cual no disponía de las materias primas suficientes para posicionarla como una empresa global. Por el otro lado, YPF era una de las empresas petroleras privadas más grandes de América Latina, y con un stock de reservas probadas suficientemente tentadoras para que REPSOL se interesara en este mercado. Pero si había algo que jugaba a favor de su ingreso al sector, era la desesperación pública que exhibía el gobierno menemista de conseguir fondos líquidos para cubrir sus compromisos internacionales a la vez de sanear los grandes baches fiscales que su administración mostraba desde hacía varios años. A mediados de 1998, el gobierno avizoraba la posibilidad de vender su restante paquete accionario $(14,99 \%)$, reteniendo la acción de oro a partir de mantener la suma simbólica de 1.000 acciones, que le posibilitó tener un director de doce y un síndico sobre tres en la empresa. Finalmente, en 1999 REPSOL tomaría el 98,3\% del total del paquete accionario de YPF, volviéndose la petrolera más importante de la Argentina, y una de las mayores empresas privadas a nivel internacional.

Sin embargo, el arribo de la empresa española a Argentina significó un agresivo plan de reestructuración de activos estratégicos y un conjunto de desinversiones programadas a fin de capitalizar a REPSOL (España), una empresa que se había vuelto tan significativa como altamente endeudada, en desmedro de las empresas que ahora controlaba alrededor del mundo. A partir del análisis de los balances de YPF desde 1999 en adelante, es posible afirmar que ésta desarrolló dos grandes mecanismos de capitalización vía desinversión programa en activos de YPF que REPSOL (España) consideraba como no estratégicos. El primero fue la transferencia de activos desde las empresas controladas hacia su casa matriz; el segundo, fue la venta de activos a terceros, que terminaría significando ingresos por US\$ 3.500.000.000 para la empresa española.

Respecto al primer mecanismo, rápidamente entre 1999 y 2001, YPF REPSOL logró transferir a su casa matriz española las participaciones que YPF tenía en Perú (YPF Perú y Refinadores del Perú), en Brasil (YPF Brasil S.A.) como también en Ecuador y Colombia a REPSOL, por un total aproximado de US\$ 535.000.000. Asimismo, REPSOL pasó a disponer de los activos que YPF tenía en Venezuela a través de Maxus Venezuela y de Maxus Guarapiche, por un total de US\$ 70.000.000. Finalmente, en 2002 se transfirió a REPSOL las inversiones de YPF en Bolivia (en Andina y Maxus Bolivia), por un total de casi US\$ 900.000.000.

Respecto al segundo, en 2001 REPSOL se deshizo de la participación que 
YPF tenía en Crescendo Resources L.P, una empresa norteamericana que producía gas, logrando obtener unos US\$ 624.000 .000 extras. También se vendieron las acciones que YPF tenía en Chile (las de Oleoducto Trasandino Argentina y Oleoducto Trasandino Chile) por US\$ 66.000.000, como también se deshizo de las acciones que YPF Internacional tenía en Canadá (al vender Bitech Petroleum Corporation a la rusa Lukoil) como en Indonesia (al desprenderse primero de sus participaciones minoritarias como YPF Blora, YPF Maxus Southeast Sumatra, YPF Java Baratlaut, YPF Madura Barat, YPF Poleng y PT IIAPCO Services, para que en 2003 terminara vendiendo YPF Indonesia por US\$ 139.000.000). En Argentina, primero vendió la participación de YPF en Electricidad Argentina S.A., para luego transferir las inversiones en Eg3 (activos cedidos a Petrobras) como en PBB Poli Sur S.A. y en Petroken Petroquímica Ensenada S.A.

Ambos mecanismos produjeron una merma en la capitalización de YPF, como un repliegue de su estrategia de inserción internacional (expandida durante los noventa, desde la gestión del ex presidente José Estenssoro) a los límites del mercado nacional. En este sentido, se explica la estrategia de una empresa esquirlada. A través de YPF, REPSOL es el reflejo del desarrollo de una estrategia de sobreexplotación de los recursos naturales como mecanismo de acumulación de capital en Argentina desplegado por parte del capital trasnacional.

En términos concretos, esta estrategia se traduce en cifras contundentes.

En relación a la extracción petrolera, entre 1999 y 2010 la misma cayó 10.329 miles de $\mathrm{m}^{3}$, mientras que para el mismo período la extracción de YPF sufrió una caída de 10.147 miles de $\mathrm{m}^{3}$ (-43\% entre período): es decir que YPF explica el 98\% de la caída general de la extracción de toda la industria desde que entró REPSOL entró a Argentina, 1999.

En cuanto a la acumulación de reservas de petróleo, YPF tuvo una caída de 118.000 .000 de $^{3}$ de reserva probadas entre 1999 y 2010 (de 182.000.000 a 64.000.000 de $\mathrm{m}^{3}$ ), lo que significa una disminución de sus stocks de $-64 \%$, mientras que el total de la industria presentó una pérdida de 174.800 .000 de cúbicos de reservas (de 488.200 .000 a 313.000.000 de $\mathrm{m}^{3}$ ), que significa una caída de $-35 \%$. De ese total que ha caído el stock de reservas de petróleo crudo argentino, YPF explica el 67\%. Inclusive, resulta llamativo el desempeńo que YPF ha tenido en uno de los megayacimientos más importantes del país, Loma La Lata, perteneciente a la Cuenta Neuquina. Si en 1999 disponía de un stock de $18.800 \mathrm{mil} \mathrm{m}^{3}$ de reservas, tras una caída del $-82 \%$, en 2010 tan sólo presentó $3.425 \mathrm{mil} \mathrm{m}^{3}$ de reservas de crudo. Seguramente, la maduración del yacimiento podría explicar parte de esa merma, pero si no estuviera asociado a la estrategia 
de acumulación de corto plazo desplegada por YPF, al extraer a mayor velocidad de la que se fueron reponiendo las reservas, no se podría explicar tamaño rendimiento del megayacimiento.

Asociado a estos procesos, la inversión en exploración de YPF fue de once pozos en promedio desde 1999 hasta 2010, mientras que el promedio anual de pozos explorados por YPF SE durante la década del ochenta fue de 110.

Finalmente, los saltos importadores de YPF significaron un costo muy alto en cuanto a la erosión sobre el superávit de la balance comercial petrolera (como también energética y general, que se agudizaría años más tarde). La estadística oficial de la Secretaría de Energía presenta que si en 1988 YPF no importaba productos petroleros y para 1999 importaba $0,087 \mathrm{mil} \mathrm{m}^{3}$ por un valor de US\$2.781.317.000.000, hacia 2009 estas cifras darían un salto sorprendente, ya que las importaciones pasarían a ser de $1.232 \mathrm{mil} \mathrm{m}^{3}$, significando un total de US\$243.000.000, es decir, un 99\% del total importado por Argentina en aquel año.

En efecto, la empresa petrolera más importante del país desarrolló una desinversión programada sobre la extracción y la exploración, produciendo una reducción considerable de los horizontes de reservas no sólo de su empresa, sino también del mercado en su conjunto. Gran parte de su estrategia se centró entonces en consolidarse en los segmentos más rentables de la industria, como ser las ventas de combustibles líquidos al mercado interno, especialmente las más caras (como las naftas premium y el gasoil), apoyándose en su posición dominante, ya que en ambas YPF explica al menos el 50\% de las ventas totales. Esta condición estructural le permitió pujar consistentemente por un aumento escalonado de precios (que fue logrando aunque desacoplado de los internacionales), impulsado por el aumento de los costos de refinación avivado tanto por las cada vez más sostenidas importaciones como por el deterioro de la extracción interna.

Sin embargo, a la sistemática caída de la extracción de crudo, de la refinación y de la inversión exploratoria de riesgo (Serrani 2012, Barrera 2012) se le sumó la presión que ejercía la importación de energía sobre la balanza comercial nacional: en 2011, llegó a ser de US\$ 9.397.000.000, un monto casi similar al superávit comercial total del país (y además, la relación entre importaciones y exportaciones de energía terminó siendo negativa en US\$ 2.931.000.000 para ese año). En este sentido, la decadencia del rendimiento del sector, el impacto que tuvo sobre el deterioro de la balanza comercial y renovado poder político del gobierno al obtener el $54 \%$ de los votos en las elecciones de 2011, hicieron que se profundizara el rumbo económico adoptado y permitió a la presidenta Fernández de Kirchner 
tomar medidas para revertir el declive del sector. En este marco, el Estado argentino recuperó YPF, su histórica empresa insignia, y con ella, recobró un papel central como garante en la búsqueda de la soberanía energética nacional.

\section{LA EXPROPIACIÓN DE YPF Y EL CAMBIO DE REGLAS EN LA BÚSQUEDA DEL AUTOABASTECIMIENTO ENERGÉTICO}

Las transformaciones en curso en el ámbito petrolero nacional reflejan la revitalización del fundamental rol estatal para la planificación y el desarrollo económico. Luego de veinte años de reformas estructurales en la industria petrolera, que incluyó la venta de la empresa estatal más importante de la historia argentina, las leyes y decretos sancionados a desde finales de 2011 son un intento de revertir la tendencia neoliberal de completa desregulación en el ámbito de los hidrocarburos, que llevó a la perdida de autoabastecimiento nacional, a una caída sostenida del horizonte de reservas petroleras y a una importación energética record en el país. Y esta reversión se hizo a partir de retomar una activa participación estatal sobre esta industria estratégica para el desarrollo económico del país.

En octubre de 2011, con la sanción del Decreto N. ${ }^{\circ} 1.722 / 2011$ se inició el camino para finalizar los privilegios institucionalizados en el proceso de acumulación de capital de las empresas petroleras derivado de las reformas estructurales neoliberales. El decreto daba de baja el régimen diferencial que desde 1989, eximía la liquidación en el país de hasta el 70\% de las divisas obtenidas por las exportaciones de commodities de las actividades minera y petrolera. En este sentido, el gobierno abogó criterios de equidad, ya que habiéndose modificado las circunstancias que dieran origen a las excepciones tributarias, y con la finalidad de un trato igualitario respecto de las demás actividades productivas, era necesario restablecer para las empresas petroleras y mineras la obligatoriedad del ingreso y negociación en el mercado de cambios de la totalidad de las divisas provenientes de sus operaciones de exportación (de conformidad con lo oportunamente establecido por el Decreto N. ${ }^{\circ} 2.581$ del 1964). La razón que motorizó la política no era menor, ya que las proyecciones de fuga de capitales para ese año estimaban alcanzar el record histórico de 2008, cercano a los US\$ 23.165.000.000 (casi la mitad de las reservas del Banco Central).

En este sentido, son varios los estudios que muestra que el comportamiento observado por las empresas privadas energéticas en el país, a partir de la desregulación y privatización de los hidrocarburos, ha sido privilegiar la maximización de ganancias en el corto plazo y la remisión de las utilidades al exterior (Barrera 2012, Kozulj 2012, Mansilla y Perrone 2010, Sabbatella 2012). En este sentido, el modelo 
de gestión privado de la industria petrolera nacional que emergió a partir de la implementación de las reformas neoliberales, provocó una lógica de acumulación de capital cortoplacista y de sobre-explotación de los recursos petroleros (descubiertos en su mayoría por los esfuerzos exploratorios realizados mientras YPF era estatal), producto de vínculos privilegiados con el Estado antes que por un desarrollo de mecanismos virtuosos y eficientes de mercado (Serrani 2012); y en esta dirección, esta lógica de acumulación privilegiada resultó estructuralmente incompatible con la necesidad de contar con una disponibilidad de energía suficiente para garantizar el desarrollo del aparato productivo nacional, a un costo que asegure las ventajas competitivas de los productos elaborados en el país, tanto en el mercado interno como en el exterior. El cumplimiento de estos objetivos nacionales postula un aumento de la planificación de largo plazo que asuma la explotación racional de recursos, la búsqueda de nuevas fuentes de energía, la diversificación energética y asegure su disponibilidad a futuro.

En este marco de estas preocupaciones sociales y económicas fue que se sancionaron dos leyes trascendentes para revertir la organización promercado de esta industria.

En mayo de 2012, y con amplia mayoría de ambas cámaras parlamentarias, se aprobó la Ley N. ${ }^{\circ} 26.741$ de Soberanía Hidrocarburífera de la República Argentina. Allí se declaró de interés público nacional y como objetivo prioritario para el país el logro del:

[...] autoabastecimiento de hidrocarburos así como la exploración, explotación, industrialización, transporte y comercialización de hidrocarburos, a fin de garantizar el desarrollo económico con equidad social, la creación de empleo, el incremento de la competitividad de los diversos sectores económicos y el crecimiento equitativo y sustentable de las provincias y regiones.

En líneas generales, los objetivos prioritarios y los principios de la política de hidrocarburos nacional establecidos por la ley buscaron revertir el largo ciclo de dominio neoliberal en la explotación de los recursos naturales hidrocarburíferos en Argentina, dejando el Estado un papel central en la organización y desarrollo de esta industria. Así fue como en la misma ley se declaró de utilidad pública y sujeto a expropiación el 51\% del patrimonio de YPF S.A. y REPSOL YPF Gas S.A (pertenecientes a REPSOL, sus controlantes o controladas, en forma directa o indirecta), como un instrumento estatal para retomar las actividades empresarias en el sector, acorde con el resto de los grandes países industriales de la región: Brasil y México, como también del resto de los países con reservas de 
petróleo y gas (Ecuador, Bolivia, Venezuela, Colombia). Al mismo tiempo, se creó el Consejo Federal de Hidrocarburos compuesto por el Ministerio de Economía, el Ministerio de Planificación Federal, Inversión Pública y Servicios, el Ministerio de Trabajo, el Ministerio de Industria y los Estados provinciales, para que el desarrollo de la política energética nacional sea diseñado federalmente.

En definitiva, la Ley N. 26.741 declaró de interés público nacional y como objetivo prioritario el logro del autoabastecimiento de hidrocarburos; además estableció que el Poder Ejecutivo Nacional, en su calidad de autoridad a cargo de la fijación de la política en la materia, será el encargado de dar cumplimiento a la ley en asociación tanto con los Estados provinciales como con el capital público y privado, nacional e internacional. En esta dirección, resultaba necesario revertir la tendencia esquiva a la inversión de riesgo en exploración que habían demostrado el conjunto de empresas privadas petroleras, en especial la YPF controlada por REPSOL.

Es así como en junio de 2012 se sancionó el Decreto N. ${ }^{\circ}$ 1.277/2012 que reglamenta la ley anterior y avanza en un tema prioritario que la Ley $\mathrm{N}$. 26.741 no había detallado. A los fines de dar cumplimiento a los principios de las nuevas reglas de juego en la industria hidrocarburífera nacional, se creó la Comisión de Planificación y Coordinación Estratégica del Plan Nacional de Inversiones Hidrocarburíferas para llevará adelante el Plan Nacional de Inversiones Hidrocarburíferas. Esta comisión busca asegurar y promover las inversiones necesarias para garantizar el autoabastecimiento en materia de hidrocarburos, como también establecer medidas de referencias para controlar los precios internos (que hasta la sanción de la ley que expropió el 51\% de YPF eran fijados por la lógica del funcionamiento oligopolizado de las firmas privadas). Además, busca la integración del capital público y privado, nacional e internacional, en alianzas estratégicas dirigidas a la exploración y explotación de hidrocarburos convencionales y no convencionales, la promoción de la industrialización y la comercialización de los hidrocarburos con alto valor agregado y la protección de los intereses de los consumidores relacionados con el precio, calidad y disponibilidad de los derivados de hidrocarburos.

En definitiva, la nueva orientación de la política hidrocarburífera nacional tiene por delante el enorme desafío de revertir dos décadas de plena decadencia de los indicadores de rendimiento de la industria y de sobre-explotación de los recursos hidrocarburíferos como estrategia de acumulación de las empresas privadas. Sin embargo, en el muy corto plazo, la nueva estructura legal del mercado petrolero y la estructura accionaria de YPF evidencian cierta atenuación de las tendencias previas. 
Tomando los meses de enero a septiembre desde 2004 y 2011, la extracción de crudo descendía a una tasa de $-6,4 \%$ anual; pero para esos mismos meses en 2012, la extracción aumentó un 6,1, quebrando la tendencia a la baja de los anteriores ocho años (CIFRA 2012). En cuanto al gas, el declive había sido de -6,7\% anual, para que en 2012 esa tendencia, a pesar de seguir siendo negativa $(-2 \%)$ atenúe la tendencia anterior a la baja promedio (CIFRA 2012). En cuanto al procesamiento de crudo, se evidencia un cambio en el uso de la capacidad instalada de las refinerías de YPF. Al comparar la performance de YPF entre enero-abril de 2011 y 2012 y mayo-agosto de los mismos años (este último período, YPF ya en control estatal), se pueden ver pequeños cambios sustantivos. En los primeros cuatro meses de 2012 respecto a igual período del ańo anterior, la refinación descendió un $-7,4 \%$ interanual, mientras que la relación entre mayo-agosto de 2012 (gestión estatal) contra mismo período de 2011 (gestión privada de REPSOL) muestra un crecimiento de 3,9\% (CIFRA 2012).

\section{CONCLUSIONES Y PERSPECTIVAS A FUTURO}

Sin lugar a dudas, el desarrollo de un país está estrechamente enlazado con la disponibilidad y producción de energía para abastecer a su sector productivo. Para sostener ritmos de crecimiento acelerados, se necesita disponer de abundante energía. A la vez, ésta debe ser comercializada a costos que permitan transformar la ecuación energética en un vector de competitividad del resto de la económica frente a la competencia de las actividades, tanto locales como internacionales.

En los noventa, se afirmó que la globalización implicaba un retroceso del Estado frente a la lógica del mercado, permitiendo que la internacionalización de las empresas y la indeterminación de las fronteras económicas nacionales trajeran mayor comercio, mayor integración global, mayor desarrollo. Lejos de cumplirse estas profecías, la globalización financiera fue el avance de las empresas multinacionales de los países del centro sobre los mercados periféricos, implicando un deterioro de las capacidades estatales para controlar a las grandes corporaciones. Así, el poco dinámico capitalismo español encontró una oportunidad de extender sus poco eficientes empresas fuera de su territorio, a partir de participar en las privatizaciones de empresas públicas en los distintos países de países latinoamericanos. El caso de la compra de YPF por parte de REPSOL es una muestra cabal de este proceso.

Sin duda, al momento en que el Estado nacional perdió el control de YPF, fue dejando de cumplir con sus objetivos productivos estratégicos que le dio origen. Es decir, desde que fue creado en 1922, YPF había logrado 
expandir la extracción de crudo y la oferta de energía en todas sus formas, desarrollando un robusto aparato productivo industrial y tecnológico no sólo a nivel nacional, sino también regional. Asimismo, fue la responsable de ampliar la frontera hidrocarburífera nacional en base a décadas de inversión exploratoria de riesgo, y además, actuaba como empresa testigo en todos los segmentos de la industria petrolera, controlando los precios internos y buscando conseguir el autoabastecimiento energético, que recién se lograría por primera vez a comienzos de los años ochenta.

Sin embargo, el paso del neoliberalismo por la industria petrolera nacional y de la región ha dejado su huella. Pero en ninguno de los tres mayores productores (México, Venezuela y Brasil) fueron tan profundos como para que los Estados perdieran el control estratégico sobre la industria ni sobre sus petroleras estatales. Luego del evidente fracaso del modelo de gestión privada en Argentina, el país está nuevamente frente a un doble desafío: primero, lograr el autoabastecimiento energético para sostener la demanda industrial, aliviar la balanza comercial y sostener el crecimiento económico; y segundo, disciplinar a las empresas privadas, que empujaron un sistema de subexploración y sobreexplotación, en base a los nuevos lineamientos de la política hidrocarburífera nacional.

A tono con la región, se plantea el desafío de si el Estado nacional volverá a tener capacidades para tener el control estratégico sobre esta industria. La oportunidad de recuperar el perdido autoabastecimiento se presenta una vez más, ahora con un marco legal complejo, novedoso y de fuerte corte nacionalista; además que el Gobierno nacional ahora cuenta con un amplio respaldo del conjunto de los Estados provinciales petroleros.

Sin embargo, la expropiación de YPF y el nuevo marco legal no solucionan, por sí mismo, los problemas estructurales de la industria petrolera nacional. Son sólo el primer paso en la búsqueda de una nueva soberanía energética. Queda por analizar si la correlación de fuerzas sociales existentes, y la formación interna de capital, permite cumplir con los lineamientos generales que la ley postula. 


\section{REFERENCIAS}

Amsden, A. (1991). Diffusion of Development: The Late-Industrializing Model and Greater East Asia. The American Economic Review, 81 (2), 282-286.

Antelo, E. (2000). Políticas de Estabilización y Reformas Estructurales en Bolivia a partir de 1985. Santiago de Chile: CEPAL.

Ayala Espino, J. (2000). Instituciones y Economía: Una Introducción al Neoinstitucionalismo Económico. México: Fondo de Cultura Económica.

Azpiazu, D. (2003). Las Privatizaciones en la Argentina. Diagnóstico y Propuestas para una Mayor Competitividad y Equidad Social. Buenos Aires: Fundación OSDE.

Azpiazu, D. y Schorr, M. (2010). Hecho en Argentina. Industria y economía, 1976-2007. Buenos Aires: Siglo XXI Editores.

Azpiazu, D., Manzaneli, P. y Schorr, M (2012). Concentración y Extranjerización. La Argentina en la Postconvertibilidad. Buenos Aires: Capital intelectual.

Barrera, M. (2011). Análisis del Proceso de Fragmentación y Privatización de YPF: Un Estudio de su Transformación en el Marco de la Desregulación del Mercado Primario de Hidrocarburos (1989-1999). Tesis de Maestría, FLACSO, Argentina.

Barrera, M. (2012). Subexploración y Sobreexplotación: La lógica de Acumulación del Sector Hidrocarburífero en Argentina. Apuntes para el Cambio, 2, 19-35.

Basualdo, E. (2006). Ensayos de Historia Económica Argentina. Deuda Externa y Sectores Dominantes desde Mediados del Siglo XX a la Actualidad. Buenos Aires: Siglo XXI Editores.

Bellini, C. y Rougier, M. (2008). El Estado Empresario en la Industria Argentina. Conformación y Crisis. Buenos Aires: Editorial Manantial.

Beltrán, G. (2011). Las Paradojas de la Acción Empresaria. Las Asociaciones del Empresariado Argentino y la Persistencia de las Reformas Estructurales. En Pucciarelli, A. (Ed.), Los años de Menem. La Construcción del Orden Liberal. Buenos Aires: Siglo XXI Editores. 
Bension, A. (2006). Las Reformas Económicas de Uruguay (1974-2004). Santiago de Chile: CEPAL.

Bondenar-Gassedat, M. J. S. (2010). Tendencia de las Inversiones Petroleras en la Argentina. Un Caso Más de las Transformaciones del Mercado Petrolero Mundial.H-Industri@, 5 (8), 1-21.

Bonilla Sánchez, A. y Suárez Guevara, S. (2008). Los Grandes Cambios del Mercado Mundial de Petróleo: Visión de Conjunto. En Suárez Guevara, S., Bonilla Sánchez, A. y Palacios I. (Eds.), Cambios en las Industrias Petrolera y de la Energía. México: Universidad Nacional Autónoma de México.

Camou, A. (1997). Los Consejeros el Príncipe. Saber Técnico y Política en los Procesos de Reforma Económica en América Latina. Nueva Sociedad, 152, 54-67.

Campodónico, H. (2004). Reformas e Inversión en la Industria de Hidrocarburos de América Latina. Santiago de Chile: CEPAL.

Canitrot, A. (1980). La Disciplina como Objetivo de la Política Económica. Desarrollo Económico. Revista de Ciencias Sociales, 19 (76), 453-475.

. (1983). Orden Social y Monetarismo. Cuadernos del CEDES, 7, 5-50.

Castellani, A. (2009) Estado, Empresas y Empresarios. La Conformación de Ámbitos Privilegiados de Acumulación entre 1966 y 1989. Buenos Aires: Editorial Prometeo.

Centro de Estudios para el Desarrollo Argentino (CENDA). (2010). La Anatomía del Nuevo Patrón de Crecimiento y la Encrucijada Actual. La Economía Argentina en el Periodo 2002-2010. Buenos Aires: Editorial Atuel.

Centro de Información y Formación de la República Argentina (CIFRA). (2012). Informe de Coyuntura No11, Noviembre de 2012. Disponible en http://www.buenosaires.cta.org.ar/IMG/pdf/cifra_-_informe_de_ coyuntura_no_11.pdf [01-05-2013].

Clavijo, F. y Valdivieso, S. (2000). Reformas Estructurales y Politica Macroeconómica: El Caso de México 1982-1999. Santiago de Chile: CEPAL. 
Correa, R. (2002). Reformas Estructurales y Crecimiento en América Latina: Un Análisis de Sensibilidad. Revista de la CEPAL, 76, 89-107.

Gadano, N. (1998). Determinantes de la Inversión en el Sector Petrolero y Gas de la Argentina. Buenos Aires: CEPAL.

Gadano, N. y Sturzeneger, F. (1998). La Privatización de Reservas en el Sector Hidrocarburífero. El caso de Argentina. Revista de Análisis Económico, 13 (1), 75-115.

Guajardo Soto, G. (Ed.). (2008). Innovación y Empresa: Estudios Históricos de México, España y América Latina. México: Universidad Nacional Autónoma de México.

Heredia, M. (2004). El Proceso como Bisagra. Emergencia y Consolidación del Liberalismo Tecnocrático: FIEL, FM y CEMA. En Pucciarelli, A. (Ed.), Empresarios, Tecnócratas y Militares. La Trama Corporativa de la Última Dictadura. Buenos Aires: Siglo XXI Editores.

Kozulj R. (2002). Balance de la Privatización de la Industria Petrolera en Argentina y su Impacto sobre las Inversiones y la Competencia en los Mercados Minoristas. Santiago de Chile: CEPAL.

Kozulj, R. y Bravo, V. (1993). La politica de Desregulación Petrolera Argentina. Antecedentes e Impactos. Buenos Aires: Centro Editor de América Latina.

Krueger, A. (1974). The Political Economy of the Rent-Seeking Society. American Economic Review, 64 (3), 291-303.

Mansilla, D. y Perrone, G. (2010). Energía en Argentina. Evolución Reciente, Actualidad y Perspectivas. Buenos Aires: Fundación Madres de Plaza de Mayo

Marichal, C. (2008). Literatura Reciente de Historia de las Empresas en México. En Guajardo Soto, G. (Ed.), Innovación y Empresa: Estudios Históricos de México, España y América Latina. México: Universidad Nacional Autónoma de México.

Montamat, D. (2005). La Energía Argentina. Otra Victima del Desarrollo Ausente. Buenos Aires: Editorial El Ateneo

Pasco-Font, A. (2000). Politicas de Estabilización y Reformas Estructurales: Perú. Santiago de Chile: CEPAL. 
Penha Cysne, R. (2000). Aspectos Macro e Microeconômicos das Reformas Brasileiras. Santiago de Chile: CEPAL.

Pucciarelli, A. (2002). La democracia que Tenemos. Buenos Aires: Libros del Rojas de la UBA.

. (Ed.). (2011). Los Años de Menem. La construcción del Orden Liberal. Buenos Aires: Siglo XXI Editores.

Rougier, M. (2010). Estudios sobre la Industria Argentina. Politicas de Promoción y Estrategias Empresariales 2. Buenos Aires: Editorial Lenguaje Claro.

Sabbatella, I. (2012). La Política Petrolera de la Posconvertibilidad: De la Herencia Neoliberal a la Expropiación de YPF. Argumentos. Revista de Critica Social, 14, 149-180.

Sabbatella, I. y Serrani, E. (2011). A 20 años de la privatización de YPF. Balance y perspectivas. Voces en el Fénix, II (10). Disponible en http://www.vocesenelfenix.com/content/20-a\%C3\%B1os-de-laprivatizaci\%C3\%B3n-de-ypf-balance-y-perspectivas [01-06-2013].

Sáinz, P. y Calcagno, A. (1999). La Economía Brasileña ante el Plan Real y sus Crisis. Santiago de Chile: CEPAL.

Salas, H. (2008). Centenario del Petróleo Argentino, 1907-2007. Buenos Aires: Editorial Instituto Argentino del Petróleo y del Gas.

Schorr, M. (2005). Cambios en la Estructura y el Funcionamiento de la Industria Argentina entre 1976 y 2004. Un Análisis Socio-Histórico y de Economía Política de la Evolución de las Distintas Clases Sociales y Fracciones de Clase durante un Periodo de Profundos Cambios Estructurales. Tesis de Doctorado (Ciencias Sociales), FLACSO, Argentina.

Schvarzer, J. (1979). Empresas Públicas y Desarrollo Industrial en Argentina. Economia de América Latina. Revista de Información y Análisis de la Región, 3, 45-68.

. (1982). Expansión Económica del Estado Subsidiario 1976-1981. Buenos Aires: CISEA.

Serrani, E. (2012). Estado, Empresarios y Acumulación de Privilegio. Análisis de la industria Petrolera Argentina (1988-2008). Tesis de Doctorado (Ciencias Sociales), Universidad de Buenos Aires, Argentina. 
Serrani, E. (2013). América Latina y su Política Petrolera frente a las Últimas Tendencias Internacionales. Perspectivas Regionales a partir del Análisis de Brasil y Argentina. Foro Internacional, LIII (211), 182213.

Serrani, E. y Castellani, A. (2010). La Persistencia de los Ámbitos Privilegiados de Acumulación en la Economía Argentina. El Caso del Mercado de Hidrocarburos entre 1977 y 1999. H-Industri@, 4 (2), $1-31$.

Sidicaro, R. (2001). La Crisis del Estado y los Actores Políticos y SocioEconómicos en la Argentina (1989-2001). Buenos Aires: Libros del Rojas de la UBA.

Strauss, L. (2009). En Busca de la Consolidación del Consenso Post Híper Inflacionario. Un Análisis Ideológico de la Producción Discursiva Neoliberal a partir de los Editoriales de la Revista Novedades Económicas de Fundación Mediterránea (Febrero 1991-Diciembre 1992). Documentos de Investigación Social, 5, 1-39.

Ugarteche, O. (2012). México: Tan Lejos de Dios, tan Cerca de la Crisis. Mecanismos de Contagio Económico en América del Norte. Nueva Sociedad, 237, 65-87.

Wade, R. (1999). El Mercado Dirigido: La Teoria Económica y la Función del Gobierno en la Industrialización del Este de Asia. México: Fondo de Cultura Económica.

Yacimientos Petrolíferos Fiscales (YPF). (1994). Memoria de YPF 1993. Buenos Aires: Biblioteca del Ministerio de Economía.

Recibido: 30-11-2012

Aceptación de la versión final: 20-03-2013 